\title{
Effect of Nursing Guidelines for Nurses on Occurrence of Selected Post Therapeutic Cardiac Catheterization Complications Among Children
}

\author{
SALMA G. MOHAMED, M.Sc.*; AFKAR R. MOHAMED, D.N.Sc.*; MARWA A. IBRAHEIM, D.N.Sc.* and \\ AMAL M. ELSISI, M.D.**
}

The Department of Pediatric Nursing, Faculty of Nursing* and Department of Pediatric Cardiology**, Faculty of Medicine, Cairo University, Egypt

\begin{abstract}
Background: Pediatric cardiac catheterization has shifted from a diagnostic tool to a therapeutic one and now more applicable for therapeutic reasons.

Aim of Study: The aim of the current study was to evaluate the effect of guidelines for nurses on occurrence of selected post therapeutic cardiac catheterization complications among children.
\end{abstract}

Subjects and Methods: Quasi-experimental design (PrePosttest) was used to achieve the aim of the current study. A convenient sample of 30 nurses and 60 children having cardiac defects undergoing cardiac catheterization were participated in the current study; children were divided into two equal groups: 30 as a control group and 30 as a study group and nurses were the same for the study and control group of children. The current study was conducted at post cardiac catheterization Intensive Care Unit at Cairo University Specialized Pediatric Hospital (CUSPH). The required data was collected through: 1- Structured interview (questionnaire); 2Nurses's knowledge and observed practice assessment sheet (pre-posttest) and 3- Post cardiac catheterization assessment sheet.

Results: The study's results revealed that, children in the study group exposed to less post cardiac catheterization complications such as weak or absent pulse, hypotension and hypothermia; than children in the control group. There was statistically significance difference between the total mean score of nurses' knowledge before and after implementation of the nursing guidelines.

Conclusion: The study concluded that nurses who received nursing guidelines sessions had improved outcomes in relation to less complications on children they were caring. Recommendation: It was recommended that provision of nursing guidelines of children undergoing cardiac catheterization is mandatory for fewer occurrences of complications. Simple Arabic illustrated booklet about cardiac catheterization care for children undergoing $\mathrm{CC}$ should be available in every post $\mathrm{CC}$ unit.

Correspondence to: Dr. Salma G. Mohamed, The Department of Pediatric Nursing, Faculty of Nursing, Cairo University, Egypt
Key Words: Cardiac catheterization - Nursing guidelines Post cardiac catheterization complications.

\section{Introduction}

HEART diseases in pediatric patients are life threatening events; that affect the child's health and family. About 1 in 120 babies born each year in the United States has a heart disease. Heart disease is acquired or congenital. Congenital heart defects (CHDs) are structural problems with the heart present at birth. They result when a problem occurs during heart development soon after conception; it has to occur during the first 8 to 12 weeks of gestation. The specific type of cardiac malformation produced varies depending on the environmental trigger and its timing within the vulnerable period. Most alterations in cardiovascular function in children are the result of defects in the heart that are present at birth as CHD. Defects range in severity from simple problems, such as "holes" between chambers of the heart, to very severe malformations, such as complete absence of one or more chambers or valves.

The etiologic factor in CHD is not known, in more than $90 \%$ of cases. However, several factors are associated with a higher than expected incidence of the defect. These include prenatal factors such as maternal rubella infection during pregnancy, maternal alcoholism, maternal age over 40 years, and maternal insulin-dependent diabetes. CHD prevalence has increased likely due to better detection and improved survival. Acquired heart diseases (AHD) are diseases affecting the heart and blood vessels that appear in an individual after 
birth include: Cardiomyopathy, endocarditis, myocarditis, pericarditis, kawasaki disease, arrhythmia, hypertension and rheumatic fever. Most frequently diagnosed are rheumatic fever and kawasaki disease [1].

With advanced medical care, more children born with CHD are surviving and because of recent advances in the diagnostics, medical treatment, and surgical techniques over the last two decades, the mortality rate of children with CHD has decreased. There are several treatment strategies for the great variety of CHD that essential to provide the best care to those children. Some of these treatment strategies are open heart surgery, medical treatment and cardiac catheterization [2]

An obvious advancement has occurred in the field of diagnostic and interventional cardiac catheterization for the aim of improving the functioning of a heart that is working abnormally. Cardiac catheterization $(\mathrm{CC})$ is a medical procedure during which a catheter is inserted into a vein or artery in a child; usually from a groin or jugular access site. Pediatric CC is a unique specialty including a wide range of diagnostic and therapeutic techniques applied to a diverse group of congenital and acquired heart diseases [3] .

Cardiac catheterization plays a key role for diagnostic precision and is considered the standard of care before initiation of therapy and for ongoing evaluation of therapeutic strategies. Diagnostic $\mathrm{CC}$ in children in some difficult cases is still having a gold standard role because meaningful and accurate data must be acquired for the presurgical evaluation of children with CHD to better guide clinical decisions and increasing safety and efficacy of surgery. Pediatric cardiac catheterization has shifted from a diagnostic tool to a therapeutic one and now more applicable for therapeutic reasons

Therapeutic CC procedures are used as an alternative to open-heart surgery when possible because of the dramatic changes that have taken place in the pediatric cardiac catheterization laboratory. Therapeutic $\mathrm{CC}$ describes procedures where cardiac catheters are used for the aim of modification, palliation, or treatment of congenital or acquired heart defects. These therapeutic procedures include closure of septal defects "ASD, VSD", closure of PDA, expansion of narrowed passages as "pulmonary stenosis", stent placement, and the creation of holes such as septostomy, valvoplasty
The success of an interventional catheterization procedure is dependent not only on the performance of the procedure, but also on good planning prior to the procedure, coupled with providing comprehensive post catheterization care, anticipation and preparation for unexpected events. It's very important that, the symptoms, findings on clinical examination, and investigations should be reviewed by cardiac catheterization laboratory team [6].

In comparison with diagnostic $\mathrm{CC}$, therapeutic catheter procedures require more time and resources, are costlier and riskier, and demand more technical training and expertise. Both therapeutic and diagnostic procedures are associated with some risks because of their invasive nature.Several studies have demonstrated that the rate of complications is higher in therapeutic procedures than that in diagnostic procedures [7].

Catheterization procedure being invasive can have complications related to arterial and venous puncture, reactions due to contrast and complications related to the heart disease itself. With the increasing complexity of cardiac catheterization procedures, transcatheter intervention, statistics show that complications remain a significant source of morbidity and mortality in these children that requiring a high level of proficiency [8].

Cardiac catheterization associated complications including arrhythmia, massive bleeding, thromboembolism, shock, hypoxemia and vessel occlusion remain a major concern for performing the procedure, Blood loss that requires transfusion, Allergic reactions to contrast, drugs, or anesthetics, Renal insufficiency caused by contrast material and diffuse central nervous system injury that can appeared by hypothermia [7]

Another classification as "major complications included vascular occlusion, access site bleeding, retroperitoneal bleeding, loss of distal pulse, or inlab access site complication." minor complications included hematoma, pseudoaneurysm. The overall complications in pediatric $\mathrm{CC}$ have the majority of vascular and complications related to femoral access [9].

Lack of knowledge and practice from all pediatric cardiac catheterization team including "pediatric cardiologists, radiologists, laboratory technicians, and nurses" can lead to unplanned cardiac surgery and death due to a catheterization complications. Nurses who are able to promptly identify complications are in the optimal position to prompt critical action and improve patient outcomes. Thus, 
nurses that are competent in the care of a child post cardiac catheterization are able to minimize mortality and morbidity rates for these children within the post-operative period.

High quality of nursing care for children in Cardiac Intensive Care Units (CICU) demands professional nursing knowledge and practical skills, due to its specificity and complexity. Nurses must be knowledgeable about the human responses of these children; many of their responses are physiological, yet there are a multitude of psychosocial, behavioral and family responses that are also very important for the nurse to understand, diagnose and treat. A thorough nursing assessment to identify signs and symptoms provides data critical to identifying nursing-sensitive human responses, and their etiologies; these are the clinical indicators of nursing diagnoses [10]

\section{Significance of the study:}

Based on the official statistical department in Cairo University Specialized Pediatric Hospital (CUSPH) there was increase in the frequency of children having cardiac defects undergoing CC. In Egypt, there are scarce studies conducted in the field of nursing care and complications of children post cardiac catheterization. Hence, the current study was under taken to evaluate the effect of guidelines for nurses on occurrence of selected post therapeutic cardiac catheterization complications among children. Hopefully, results of the present study will help in improving the nurses' knowledge regarding care of children after CC. As well as providing guidance and recommendations that should be reflected in pediatric nursing education and providing evidenced based data that can develop nursing practice and research in the field of pediatric cardiology nursing. As well as, Standardized guidelines for post cardiac catheterization care is useful to anticipate and prevent post cardiac catheterization complications while minimizing utilization of hospital resources, so this study has two faces of benefits for nurses working in CC specialty as well as children undergoing $\mathrm{CC}$.

\section{Research hypotheses:}

1- Nurses will have higher mean scores of knowledge and practice after attending post catheterization guidelines sessions than before.

2-Children will have lesser occurrences of post cardiac catheterization complications after applications of nursing guidelines than the control group.

\section{Subjects and Methods}

Research design:

Pre-post test quasi experimental design was utilized to achieve the aim of the current study.

Setting:

The current study was conducted at the Post Cardiac Catheterization Intensive Care CUSPH At the period started from $1 / 2016$ to 8/201 6 .

\section{Study subject:}

A Convenient sample of 30 staff nurses working in post cardiac catheterization Intensive Care Unit and 60 children with congenital heart diseases undergoing cardiac catheterization participated in the study. The first 30 children received nursing care after application of nursing guidelines (study group), the second 30 children exposed to the routine nursing care (control group).

\section{Inclusion criteria:}

Children having congenital heart defects such as Ventricular Septal Defect (VSD), Atrial Septal Defect (ASD), Patent Ductus Arteriosus (PDA), Children undergoing therapeutic cardiac catheterization, Both genders and children aged from six months to five years.

\section{Exclusion criteria:}

Children undergoing diagnostic cardiac catheterization, children having any other disease e.g., hematological disorders, respiratory problems such as pneumonia or any other major congenital anomalies such as Central Nervous System (CNS) congenital anomalies and Gastrointestinal Tract (GIT) congenital anomalies.

\section{Tools for data collection:}

The required data was collected through the following tools:

\section{1- Structured Interview Sheet (questioner):}

It developed by the research investigator in Arabic language after reviewing the related literature. It includes three parts about nurses and child.

Part I: It involved eight (8) questions related to personal and professional data for nurses such as (age, qualification, marital status, certifications and years of experience in cardiac catheterization unit ... etc).

Part II: It involved twenty two (22) questions about characteristics of children such as age, weight, gender, etc. This part also contained questions about child's diagnosis, time of diagnosis, signs and symptoms of his disease etc.... 
Part III: It included post cardiac catheterization assessment data sheet. It developed by the research investigator to assess the child's general condition immediately post cardiac catheterization and revealed that no presence of complications. It included measurement of body temperature, blood pressure, conscious level, bleeding sings, skin characteristics for coldness or warmth, puncture site characteristics and postoperative pain.

\section{2- Nurses' knowledge assessment sheet (pre-post test):}

It involved thirty four (34) questions developed by the research investigator to assess nurse's knowledge regarding care of children undergoing cardiac catheterization (pre-posttest) such as: Meaning of cardiac catheterization, indications for cardiac catheterization, complications of cardiac catheterization and questions related to reported practice such as immediate post cardiac catheterization care, insertion site care and assessment of conscious level etc.

\section{3- Observetional check lists:}

To assess nurse's performance of provided care for childrenusing standardized check lists such as vital signs, puncture site care, fluid balance chart check list... .etc.

\section{4- Post cardiac catheterization complications assessment record:}

It was developed by the research investigator for the purpose of follow-up of all participants (study and control group) after the first six hours post cardiac catheterization involved all post cardiac catheterization complications such as bleeding, puncture site hematoma and hypothermia especially in small infants.

\section{Scoring system:}

For nurses' knowledge and practice each correct response/activities will take one score and the wrong or don't know response will take zero score. The total score of thirty will reflect $100 \%$, and then categorized as following: (excellent, very good, good, pass and failed) the total score of good, V good \& excellent level was considered as satisfactory while level of failed and pass evaluation was considered as unsatisfactory. Excellent level reflected score from $85 \%$ to $100 \%$, V good level reflected score from $75 \%$ to $85 \%$, good level reflected score from $65 \%$ to $75 \%$, Pass level reflected score from $60 \%$ to $65 \%$ and fail level reflected score below $60 \%$.

\section{Field work:}

Preparatory and assessment phase: Before conducting the study an official permission was obtained from the directors of Cairo University Specialized Pediatric Hospital (CUSPH), and permission from the head of post cardiac catheterization care unit also was obtained after explaining the nature of the study. The research investigator introduced self to the parents fulfilling study criteria and the aim of the study. At the day of cardiac catheterization the written informed consent was obtained from parents in both study and control groups of children according to inclusion criteria to get their acceptance. Clear and simple explanations about the aim and nature of the study were discussed by the research investigator with nurses, then nurses filled the questioner (tool 1 part I). Pretest for assessing nurses level of knowledge (tool 2) fulfilled on all nursing staff who attending day shift (morning and afternoon shift), after that the research investigator assessed nurses level of practice by using observational check list (tool 3).

\section{Implementation phase:}

Then Post cardiac catheterization nursing guidelines sessions explained to the nurses one day before cardiac catheterization through one educational session and was took about 45-60 minutes on a group of 3-5 nurses providing nursing care such as the child should lay supine position and the affected limb to be kept straight for the first 4 hours following venous access and 6 hours following arterial access, record pulse, respirations.

Arabic illustrated nursing instructions about appropriate post cardiac catheterization care for the child after therapeutic cardiac catheterization was prepared by the research investigator and it was given and explained to the nurses in the study group. It include simple information about asymptomatic congenital heart disease, cardiac catheterization (indications, preparation and its complications) and care of the puncture site, medications (antibiotics and pain management), hygienic care, fluid intake and activities; aided by the using of instructional illustrated Arabic booklet and redemonstration of practice on a doll, educational videos and pictures also utilized and distributed to each nurse.

At the day of cardiac catheterization, the research investigator filled the post cardiac catheterization assessment data sheet (tool 1, part III) for children in the study and control groups and assess presence of selected complications after six (6) hours of cardiac catheterization in both study and control groups of children. These complications 
were observed and recorded through post cardiac catheterization complications assessment record (tool 5). Data collection was conducted over eight month's period extending from January 2016 till august 2016.

\section{Validity and reliability:}

Data collection tools of the study were submitted to 5 experts in the field of pediatric surgery nursing, and pediatric cardio-thoracic surgery to test the content and face validity. The experts' agreed on the content of the tools, but recommended minor language changes that would make the information more clear and precise. The suggested changes were made. Regarding reliability, the reliability coefficients' alpha between questions was tested.

\section{Pilot study:}

A pilot study was carried out on $10 \%$ of children who have congenital heart defects and undergoing cardiac catheterization to test study tools in terms of its clarity, applicability and time required to fulfill it. The needed modifications were done, the pilot study participants were excluded from the total sample.

\section{Administrative and ethical consideration:}

A primary approval was obtained from the research ethical committee in the faculty of nursing, Cairo University. A written informed consent obtained by the research investigator after taking acceptance from the research ethical committee. The written informed consent was obtained from the parents of children after complete description of the purpose and nature of the study in order to obtain their acceptance as well as to gain their cooperation and was obtained also from participating nurses. Children and their mothers were informed that participation in the study was voluntary; mothers have rights to withdraw from the study at any time without giving any reason and without any effect on the care of their children. Confidentiality assured to each child and their mothers. For research ethical consideration and based on the basic ethical principles of beneficence, data collected firstly from the control group. Statistical design.

The collected data tabulated, and summarized. A statistical package for social studies (SPSS) version 20 was used for statistical analysis of data. Data was computerized and analyzed using appropriate descriptive and inferential statistical tests. Qualitative data were expressed as frequency and percentage. A comparison between qualitative variables carried out by using parametric Chi square test. Comparison of means was performed using paired-sample $t$-test. Correlation among variables was done using Pearson correlation coefficient. Level of significance at $p<0.05,0.001$ were used as the cut of value for statistical significance.

\section{Results}

Table (1) clarified that more than two fifths (43.3\%) of children in the study and control group had 1 to less than three years old and $(36.7 \%, 40 \%$ respectively) in both group were less than one year. Regarding children gender it was found that more than half (53.3) were male while (46.7) were female in the study group and also more than half (60) were male and (40.0) were female in the control group. There was no statistically significant difference between children in both groups regarding child age, gender. As well as, it was found that the highest percentage (36.7) of children had Atrial septal defects (ASD) in the study group while in the control group the two fifths (40.0) of children had patent ductus arterosis (PDA).

Table (2) revealed that half (50\%) of children in the study group diagnosed in the first year of life and two fifth (40\%) of children diagnosed immediately post natal and the lowest percentage diagnosed during pregnancy. The current study results indicated that an equal percentage of children in both groups had a family history of CHD. As regards family member who had $\mathrm{CHD}$, it was found that more than half of children $(60 \%$ \& $63 \%$ respectively) had affected siblings. There was no statistically significant difference between children in both groups regarding time of diagnosis of child's CHD and affected siblings in the family ( $\mathrm{X}_{2}=$ $5.688, p=.771 \& \mathrm{X}_{2}=.712, p=.466$, respectively).

It was evident from Table (3) that about $10 \%$ of children in the study group have cyanosis and high percentage of children in both group $(60.0 \%$ $\& 70 \%$ respectively) suffered from more than one signs and symptoms such as difficult breathing, difficult feeding, easily fatigability, sweating, etc. On the same line, this table revealed that more than half in both groups diagnosed by echocardiography.

Fig. (1) clarified that more than two thirds $(70 \%)$ of children in the study group, had inappropriate body weight in relation to their age while nearly one third $(30 \%)$ had appropriate body weight in relation to their age. It was found on the control group that $(43.3 \%)$ of children had inappropriate body weight in relation to their age and more than 
half $(56.7 \%)$ were appropriate in relation to their age.

Table (4) revealed that the majority $(80.0 \%)$ of children in the study group and less than two thirds $(63.3 \%)$ of children in the control group had cold extremities immediately post CC. Also the majority of children $(86.7 \%)$ in the study group and more than three quarters of children in control group (76.7\%) don't have hematoma, bleeding and insertion site pain immediately post CC. Regarding conscious level of children it was found that all children $(100 \%)$ of both groups were conscious. In relation to the presence of pain all $(100 \%)$ of children in both group have pain.

Table (5) clarified that more than $60 \%$ of assigned nurses had 20 to less than 25 years, female nurses. Regarding nurses qualifications and training courses obtained by the study sample, the results indicated that only half of nurses attended training courses as only $10 \%$ attended sessions related to cardiac catheterization, $10 \%$ attended advanced life support and $35 \%$ infection control training courses and only 5\% attended ECG and first aid courses.

Fig. (2) clarified that level of education of nurses in the current study; was $40 \%$ of nurses were in level of undergraduate students, and nearly one third were nursing institute and more than one quarter were diploma nurses.

Regarding to nurses' knowledge at Table (6) there was statistically significant difference between pre and post implementation of nursing guidelines sessions $(t=-12.783, p=0.000)$. So it was evident from this table that the total mean scores of nurses' knowledge about CC was (17.80 $\pm 2.772,26.07$ \pm 2.406 in orders).

Table (7) clarified that the vast majority (90\%) of nurses was oriented about accurate definition and aim of $\mathrm{CC}$ after guidelines sessions. It was evidenced also that the majority $(80.0 \%$ \& $86.7 \%$ respectively) of nurses were answered that they aware with complications of CC but in fact it was wrong answer before implementations guidelines sessions. The same table clarified that there was no statistically significant differences between the nurses knowledge about CC (pre, post) implementation of the nursing guidelines sessions ( $X_{2}=$ $\left.8.013, p=.237, \mathrm{X}_{2}=5.069, p=.750\right)$.

Table (8) indicated that more than three quarters of the assigned nurses $(76.7 \% \& 80 \%$ in order) put children in accurate position before and after ap- plication of nursing guidelines sessions. Regarding child's air way opening and providing chest physiotherapy more than two thirds $(70 \%)$ of nurses applied that after providing of nursing guidelines sessions. In the same line, it was found that the majority (86.7\%) of nurses assesses presence, weakness or absence of pulse and more than three quarters of nurses $(76.7 \%)$ assess puncture site of children after nursing guidelines sessions.

As regarding to nurses' practice, it was evident from Table (9) that the total mean scores of nurses' practice about care for children after cardiac catheterization was difference between before and after implementation of nursing guidelines sessions, it was $(6.27 \pm 1.311,13.80 \pm 1.883$ in orders). Statistically significant difference was detected between two readings $(t=-18.175, p=0.000)$.

Table (10) showed that children in study group were exposed to post $\mathrm{CC}$ bleeding less than children in the control group $(3.3 \% \& 16.7 \%$ in order $)$. As regarded to child's pulse in the affected limp, it was found in the current study that vast majority $(93.3 \%)$ of children in study group don't have weak or absent pulse, while half $(50 \%)$ of children in control group have weak or absent pulse. Regarding hypotension, the study results revealed that children of the study group had hypotension less than those in the control group ( $10 \% \& 40 \%$ respectively).

It was found in the current study that vast majority (93.3\%) of children in the study group doesn't expose to hypothermia and $96.7 \%$ of children in the study group don't have hematoma. It was found in the current study that no occurrence of oliguria and aspiration in children of study group, while it occurred in control group with percentage of $13.3 \%$.

Apparently, the same table showed that there was no statistically significant difference between children in both groups regarding presence of bleeding, absence or weak pulse and presence of hypothermia post cardiac catheterization $\left(X_{2}=.207\right.$, $\left.p=.649, \mathrm{X}^{2}=2.143, p=.143 \& \mathrm{X}^{2}=.089, p=.765\right)$.

The study's results revealed that there was statistically significant correlation detected between the nurses' total mean score of practice after implementation of nursing guidelines sessions and selected post cardiac catheterization complications such as presence of hypothermia and presence of tachy or bradycardia among children of the study group. 
Table (1): Percentage distribution of personal data related to children in study and control group.

\begin{tabular}{|c|c|c|c|c|c|c|}
\hline \multirow{2}{*}{$\begin{array}{l}\text { Child's } \\
\text { characteristics }\end{array}$} & \multicolumn{2}{|c|}{$\begin{array}{l}\text { Study } \\
(\mathrm{n}=30)\end{array}$} & \multicolumn{2}{|c|}{$\begin{array}{c}\text { Control } \\
(\mathrm{n}=30)\end{array}$} & \multirow{2}{*}{$X^{2}$} & \multirow[t]{2}{*}{$p$} \\
\hline & $\mathrm{N}$ & $\%$ & $\mathrm{~N}$ & $\%$ & & \\
\hline \multicolumn{7}{|c|}{ Child'sage/years: } \\
\hline <one year & 11 & 36.7 & 12 & 40 & 3.407 & .492 \\
\hline 1 to $<3$ & 13 & 43.3 & 13 & 43.3 & & \\
\hline 3 to $<5$ & 6 & 20 & 5 & 16.7 & & \\
\hline \multicolumn{7}{|l|}{ Gender: } \\
\hline Male & 16 & 53.3 & 18 & 60 & .089 & .765 \\
\hline Female & 14 & 46.7 & 12 & 40 & & \\
\hline \multicolumn{7}{|c|}{ Child diagnosis: } \\
\hline VSD & 6 & 20.0 & 8 & 26.7 & 2.746 & .840 \\
\hline ASD & 11 & 36.7 & 10 & 33.3 & & \\
\hline PDA & 9 & 30.0 & 12 & 40.0 & & \\
\hline Others & 4 & 13.3 & 0 & 0.0 & & \\
\hline
\end{tabular}

Table (2): Percentage distribution of children' diagnosis in study and control group.

\begin{tabular}{llllllll}
\hline \multirow{2}{*}{ Item } & \multicolumn{2}{c}{$\begin{array}{c}\text { Study } \\
(\mathrm{n}=30)\end{array}$} & \multicolumn{2}{c}{$\begin{array}{c}\text { Control } \\
(\mathrm{n}=30)\end{array}$} & \multirow{2}{*}{$\mathrm{X}^{2}$} & $p$ \\
\cline { 2 - 5 } & $\mathrm{N}$ & $\%$ & $\mathrm{~N}$ & $\%$ & & \\
\hline Time for diagnosis: & & & & & & \\
$\quad$ During pregnancy & 2 & 6.7 & 8 & 26.7 & 5.688 & .771 \\
Immediately postnatal & 12 & 40.0 & 8 & 26.7 & & \\
First one year & 15 & 50.0 & 12 & 40.0 & & \\
After 1st year & 1 & 3.3 & 2 & 6.7 & & \\
Affected sibling: & & & & & & \\
$\quad$ Yes & 18 & 60.0 & 19 & 63.3 & .712 & .466 \\
No & 12 & 40.0 & 11 & 36.7 & & \\
\hline
\end{tabular}

Table (3): Percentage distribution of children' complain and diagnostic evaluation in study and control group.

\begin{tabular}{|c|c|c|c|c|c|c|}
\hline \multirow[t]{2}{*}{ Item } & \multicolumn{2}{|c|}{$\begin{array}{c}\text { Study } \\
(\mathrm{n}=30)\end{array}$} & \multicolumn{2}{|c|}{$\begin{array}{c}\text { Control } \\
(\mathrm{n}=30)\end{array}$} & \multirow[t]{2}{*}{$X^{2}$} & \multirow[t]{2}{*}{$p$} \\
\hline & $\mathrm{N}$ & $\%$ & $\mathrm{~N}$ & $\%$ & & \\
\hline \multicolumn{7}{|l|}{ Signs \& symptoms: } \\
\hline Cyanosis & 3 & 10.0 & 0 & 0.0 & 6.339 & .175 \\
\hline $\begin{array}{l}\text { Tachycardia, } \\
\text { arrhythmia }\end{array}$ & 9 & 30.0 & 8 & 26.7 & & \\
\hline More than one signs & 18 & 60.0 & 21 & 70.0 & & \\
\hline $\begin{array}{l}\text { Difficult feeding, } \\
\text { easy fatigability }\end{array}$ & 18 & 60.0 & 15 & 50 & & \\
\hline \multicolumn{7}{|l|}{ Diagnostic tests: } \\
\hline Prenatal 3D & 1 & 3.3 & 5 & 16.7 & 3.188 & .956 \\
\hline Echocardiography & 16 & 53.3 & 17 & 56.7 & & \\
\hline Signs \& symptoms & 3 & 10.0 & 2 & 6.7 & & \\
\hline More than one test & 10 & 33.3 & 6 & 20.0 & & \\
\hline
\end{tabular}

Table (4): Percentage distribution of puncture site assessment \& conscious level immediately post $\mathrm{CC}$ for children in study and control group.

\begin{tabular}{|c|c|c|c|c|c|c|}
\hline \multirow[t]{2}{*}{ Item } & \multicolumn{2}{|c|}{$\begin{array}{l}\text { Study } \\
(\mathrm{n}=30)\end{array}$} & \multicolumn{2}{|c|}{$\begin{array}{c}\text { Control } \\
(n=30)\end{array}$} & \multirow[t]{2}{*}{$\mathrm{X}^{2}$} & \multirow[t]{2}{*}{$p$} \\
\hline & $\mathrm{N}$ & $\%$ & $\mathrm{~N}$ & $\%$ & & \\
\hline \multicolumn{7}{|l|}{ Skin characteristics: } \\
\hline Warm & 6 & 20.0 & 11 & 36.7 & .036 & .850 \\
\hline Cold & 24 & 80.0 & 19 & 63.3 & & \\
\hline \multicolumn{7}{|l|}{ Conscious level: } \\
\hline Conscious & 30 & 100.0 & 30 & 100.0 & & \\
\hline Unconscious & 0 & 0.0 & 0 & 0.0 & & \\
\hline \multicolumn{7}{|l|}{$\begin{array}{l}\text { Puncture site } \\
\text { characteristics: }\end{array}$} \\
\hline $\begin{array}{l}\text { Presence of } \\
\text { hematoma, } \\
\text { bleeding, insertion } \\
\text { site pain }\end{array}$ & 3 & 10.0 & 1 & 3.3 & 1.405 & .843 \\
\hline None of the above & 26 & 86.7 & 23 & 76.7 & & \\
\hline Others & 1 & 3.3 & 6 & 20.0 & & \\
\hline \multicolumn{7}{|l|}{ Presence of pain: } \\
\hline Present & 30 & 100.0 & 30 & 100.0 & Constant & \\
\hline
\end{tabular}

Table (5): Percentage distribution of personal data related to assigned nurses in the current study.

\begin{tabular}{lll}
\hline Item & $\mathrm{N}$ & $\%$ \\
\hline Nurses age: & & \\
$20-25$ & 18 & 60 \\
$25-35$ & 9 & 30.0 \\
$35-45$ & 3 & 10.0 \\
Gender: & & \\
$\quad$ Male & 11 & 36.7 \\
$\quad$ Female & 19 & 63.3 \\
Nurses qualifications: & & \\
$\quad$ Qualified in CC care & 3 & 10.0 \\
$\quad$ General nursing practices & 15 & 50.5 \\
$\quad$ such as (infection control, CPR) & & \\
$\quad$ No courses training & 12 & 40.0 \\
\hline
\end{tabular}

Table (6): Percentage distribution of personal data related to assigned nurses in the current study.

\begin{tabular}{lcccc}
\hline Item & Pre & Post & $t$ & $p$ \\
\hline Minimal & 13 & 20 & -12.783 & 0.000 \\
Maximum & 25 & 29 & & \\
Mean $\rightarrow$ SD & $17.80 \pm 2.772$ & $26.07 \pm 2.406$ & & \\
\hline
\end{tabular}

Significant at $p<0.000$.

Table (7): Percentage distribution of level of nurses' knowledge before and after implementation of nursing guidelines in the current study.

\begin{tabular}{|c|c|c|c|c|c|c|}
\hline \multirow{2}{*}{ Item } & \multicolumn{2}{|c|}{ Pre } & \multicolumn{2}{|c|}{ Post } & \multirow{2}{*}{$X$} & \multirow{2}{*}{$p$} \\
\hline & $\mathrm{N}$ & $\%$ & $\mathrm{~N}$ & $\%$ & & \\
\hline \multicolumn{7}{|c|}{ Level of satisfaction: } \\
\hline Excellent & 0 & 0.0 & 21 & 70.0 & 8.262 & .220 \\
\hline$V$ good & 2 & 6.7 & 5 & 16.7 & & \\
\hline Good & 3 & 10.0 & 4 & 13.3 & & \\
\hline Pass & 13 & 43.3 & 0 & 0.0 & & \\
\hline Fail & 12 & 40.0 & 0 & 0.0 & & \\
\hline
\end{tabular}


Table (8): Percentage Distributionof nurses' observational checklists about care of children post $\mathrm{CC}(\mathrm{n}=30)$.

\begin{tabular}{|c|c|c|c|c|c|c|}
\hline \multirow{2}{*}{ Item } & \multicolumn{2}{|c|}{ Pre } & \multicolumn{2}{|c|}{ Post } & \multirow{2}{*}{$\mathrm{X} 2$} & \multirow{2}{*}{$p$} \\
\hline & $\mathrm{N}$ & $\%$ & $\mathrm{~N}$ & $\%$ & & \\
\hline \multicolumn{7}{|c|}{ Semi setting position: } \\
\hline Done & 23 & 76.7 & 24 & 80 & .186 & .666 \\
\hline Not done & 7 & 23.3 & 6 & 20 & & \\
\hline \multicolumn{7}{|c|}{ Air way opening: } \\
\hline Done & 21 & 70.0 & 22 & 73.3 & .130 & .719 \\
\hline Not done & 9 & 30.0 & 8 & 26.7 & & \\
\hline \multirow{2}{*}{\multicolumn{7}{|c|}{$\begin{array}{l}\text { Assess presence, weakness } \\
\text { or absence of pulse: }\end{array}$}} \\
\hline & & & & & & \\
\hline Done & 5 & 16.7 & 26 & 86.7 & 3.692 & .055 \\
\hline Not done & 25 & 83.3 & 4 & 13.3 & & \\
\hline \multicolumn{7}{|c|}{$\begin{array}{l}\text { Check chest condition \& } \\
\text { air entry: }\end{array}$} \\
\hline Done & 2 & 6.7 & 14 & 46.7 & .010 & .922 \\
\hline No done & 28 & 93.3 & 16 & 53.3 & & \\
\hline \multicolumn{7}{|c|}{ Puncture site assessment: } \\
\hline Done & 3 & 10.0 & 23 & 76.7 & 3.499 & .061 \\
\hline Not done & 27 & 90.0 & 7 & 23.3 & & \\
\hline \multicolumn{7}{|c|}{ Monitor intake \& output: } \\
\hline Done & 23 & 76.7 & 27 & 90 & .186 & .666 \\
\hline Not done & 7 & 23.3 & 3 & 10 & & \\
\hline
\end{tabular}

Table (9): Comparison between total mean score of nurses' practice before and after implementation of nursing guidelines in the current study.

\begin{tabular}{lllcc}
\hline Item & Pre & Post & $t$ & $p$ \\
\hline Minimal & 4 & 10 & -18.175 & $0.000^{*}$ \\
Maximum & 9 & 17 & & \\
Mean \pm SD & $6.27 \pm 1.311$ & $13.80 \pm 1.883$ & & \\
\hline
\end{tabular}

Significant at $p<0.000$.

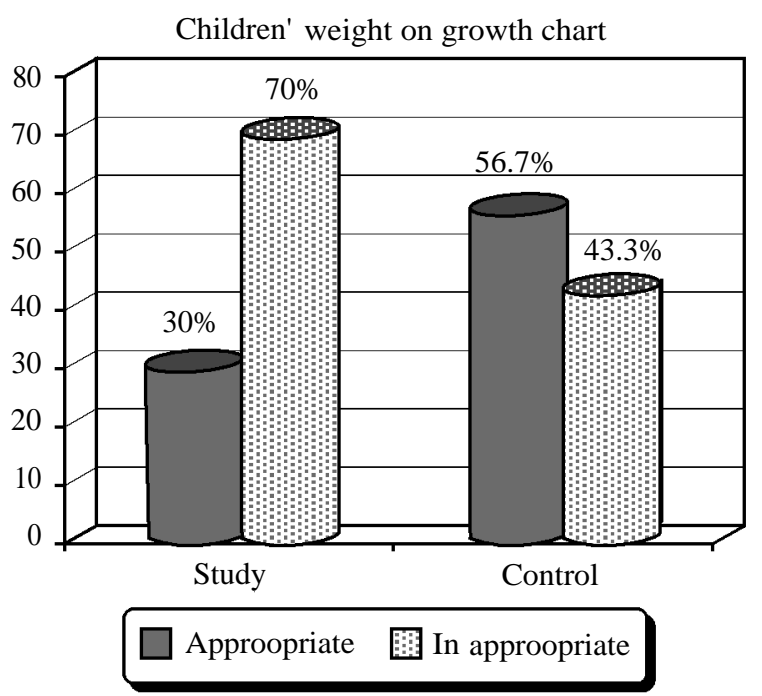

Fig. (1): Body weight amongchildren in study and control group.
Table (10)

\begin{tabular}{|c|c|c|c|c|c|c|}
\hline \multirow{2}{*}{ Item } & \multicolumn{2}{|c|}{$\begin{array}{c}\text { Study } \\
(\mathrm{n}=30)\end{array}$} & \multicolumn{2}{|c|}{$\begin{array}{c}\text { Control } \\
(n=30)\end{array}$} & \multirow[t]{2}{*}{$X^{2}$} & \multirow{2}{*}{$p$} \\
\hline & $\mathrm{N}$ & $\%$ & $\mathrm{~N}$ & $\%$ & & \\
\hline \multicolumn{7}{|l|}{ Bleeding: } \\
\hline Present & 1 & 3.3 & 5 & 16.7 & .207 & 649 \\
\hline Not present & 29 & 96.7 & 25 & 83.3 & & \\
\hline \multicolumn{7}{|l|}{ Tachycardia or } \\
\hline \multicolumn{7}{|l|}{ bradycardia: } \\
\hline Present & 3 & 10.0 & 9 & 30.0 & 1.429 & .232 \\
\hline Not present & 27 & 90.0 & 21 & 70.0 & & \\
\hline \multicolumn{7}{|l|}{ Weak or absent } \\
\hline \multicolumn{7}{|l|}{ pulse: } \\
\hline Present & 2 & 6.7 & 15 & 50.0 & 2.143 & .143 \\
\hline Not present & 28 & 93.3 & 15 & 50.0 & & \\
\hline \multicolumn{7}{|l|}{ Arrhythmia: } \\
\hline Present & 1 & 3.3 & 4 & 13.3 & .159 & 690 \\
\hline Not present & 29 & 96.7 & 26 & 86.7 & & \\
\hline \multicolumn{7}{|l|}{ Hypotension: } \\
\hline Present & 3 & 10.0 & 12 & 40.0 & .062 & .653 \\
\hline Not present & 27 & 90.0 & 18 & 60.0 & & \\
\hline \multicolumn{7}{|l|}{ Hypothermia: } \\
\hline Present & 2 & 6.7 & 12 & 40.0 & .089 & .765 \\
\hline Not present & 28 & 93.3 & 18 & 60.0 & & \\
\hline \multicolumn{7}{|l|}{ Hematoma: } \\
\hline Present & 1 & 3.3 & 7 & 23.3 & .315 & .575 \\
\hline Not present & 29 & 96.7 & 23 & 76.7 & & \\
\hline \multicolumn{7}{|l|}{ Aspiration: } \\
\hline Present & 0 & 0.0 & 4 & 13.3 & Constant & Constant \\
\hline Not present & 30 & 100.0 & 26 & 86.7 & & \\
\hline
\end{tabular}
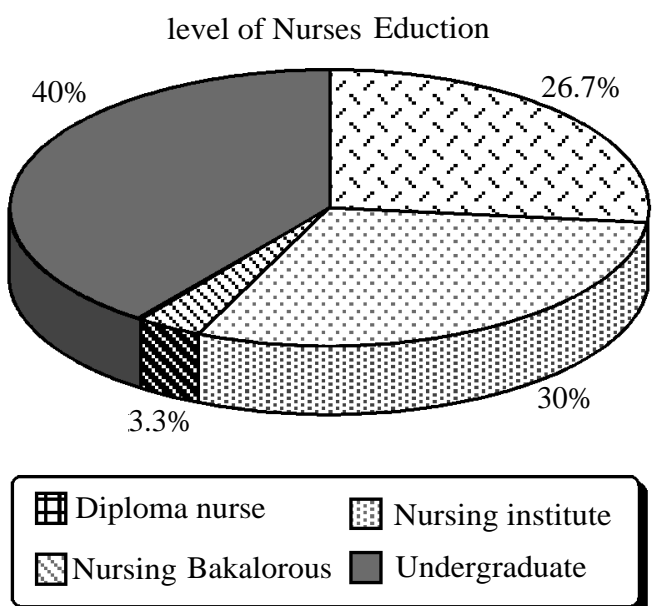

Fig. (2): Level of nurses education. 


\section{Discussion}

Pediatric cardiac catheterization has shifted from a diagnostic tool to a therapeutic one and now more applicable for therapeutic reasons [5] The aim of the current study was to evaluate the effect of guidelines for nurses on occurrence of selected post therapeutic cardiac catheterization complications among children.

The current study indicated that more than two fifth of children in both groups aged from 1 to less than three year and more than one third of children in both study and control group were less than one year. As well as, another study conducted by [11] who studied pediatric cardiac catheterization: Experience of a tertiary care pediatric cardiac center and found that the majority of children undergoing $\mathrm{CC}$ of a cyanotic patient was more than 1 year age and less than 1 year were less than one quarter. The issue of operability of a cyanotic congenital heart defects decision based on clinical findings and echocardiography only, after giving chance for a spontaneous closure within the first 18 months of life. If it does not spontaneously close, the child will most likely need corrective surgery [12].

On the same line a recent Egyptian study held by [13] at Cairo University Specialized Pediatric Hospital (CUSPH), about transcatheter closure of perimembranous ventricular septal defects (VSDs) using the Amplatzer duct occluder device, the authors founded that median age of the 28 included patients was 4 years ranging from 13 months to 12 years. In the researcher point of view, that device closure at catheterization has become increasingly popular and more familiar in young age instead of surgical closure that accompanied with morbidity.

Regarding children gender the current study represented that more than half were male in both groups and the rest were female that is supported by a study held by [14] about experience of percutaneous ventricular septal device closure, they found that nearly more than half were male and the rest of children were female. These findings go with the opinion of [15] who concluded that (ASD) and pulmonic stenosis were more common among females, whereas aortic stenosis, coarctation of the aorta were more common among males.

Concerning diagnosis among children in the study and control group, the current study indicated that more than one third of children in the study group had Atrial Septal Defects (ASD) while in the control group the highest percentage of children $(40 \%)$ had patent ductus arterosis (PDA). This result suggested higher closure of ASD and PDA through interventional
$\mathrm{CC}$ that has increasingly become a treatment for its correction. On the same line, [16] who studied Radiation Dose Benchmarks during cardiac catheterization for congenital heart disease confirmed that the majority of cases had ASD and PDA.

The current study revealed that half of the studied children diagnosed in the first year of life and two fifths diagnosed immediately postnatal and lowest percentage diagnosed during pregnancy. For the control group, two fifths of children were diagnosed in the first year of life. This result contradicted with an Egyptian study held about breast feeding pattern among infants with congenital heart diseases at Cairo University pediatric hospitals who found that time of discovery the infants' illness, was during the first week after delivery among $55 \%$ of the studies children.

In addition the study's results revealed that, less than two thirds of both children in the study and control group had affected sibling. It was supported by an Egyptian study held by [17] who studied risk factors of CHDs and illustrated that the majority of CHDs are polygenic diseases which affected by both genetic and environmental factors and the experience of CHDs affect not only the individual but also the family members. This might be an indicator of the role of heredity in the most of congenital anomalies.

The current study's results revealed that more than two thirds of children in the study group; had inappropriate body weight in relation to their age percentile, while only more than one quarter, had appropriate weight in relation to their age percentile. This is confirmed by an Egyptian study made in Cairo University Specialized Pediatric Hospital (CUSPH) by [18] who indicated that all cases were failing to gain weight. This could be due to improper feeding, activity intolerance and recurrent respiratory infections.

It was evident from the current study that the highest percentage of children in both study and control group had more than one signs and symptoms such as difficult breathing, difficult feeding, easily fatigability and sweating. On the same context [19] confirmed that most children who have lesions with left-to-right shunts include ASD, VSD, and PDA are asymptomatic. However, a very large defect can cause increased blood flow and present with symptoms of congestive heart failure, which results in shortness of breath, easy fatigability such as feeding or exercise intolerance, poor weight gain and prolonged recovery from simple respira- 
tory infections, depending on the amount of shunting.

The current study revealed that the vast majority of the study group and less than two of control group had cold extremities immediately post CC. Regarding conscious level of children it was found that children of both groups were conscious after admission to PCCICU. In relation to presence of pain all children in both groups have pain. On the same line an Egyptian study held by [20] who found that cardiac procedures are accompanied by post operative pain and anxiety. The stress response during surgery and catheterization is an unconscious systemic reaction to tissue injury that reflects autonomic, hormonal, and metabolic changes. It has long been recognized that surgery can be a very stressful experience for children.

The current study revealed that more than half of the assigned nurses, had age ranged from 20 to less than 25 years. It was found that less than two thirds of them were female while just one third were male nurses; this may be due to the dominance of females in the nursing profession and recent involvement of male in nursing career.

Regarding to training courses obtained by the studied nurses, the results of the current study indicated that only one half of nurses attended training courses as only ten percent attended sessions related to $\mathrm{CC}$, another ten percent attended advanced life support and almost one third attended "infection control" training courses and a minority of them attended ECG and first aid courses. This may be due to the shortage of nursing specialists that interferes with lack of attention of the hospital and nursing administrators to the importance of in-service and outside educational training programs.

Regarding nurses level of education; two fifth of the participants were in the level of undergraduate students, nearly one third were nursing institute and the rest of participants were diploma nurses and a minority of less than one percentage of bachelor degree nurses. This may be due to the number of educational institutions and schools graduating diploma nurses are more than the number of faculties graduating bachelor degree nurses. In addition there was significance shortage in the qualified nurses in these ICUs.

It was evident from the current study that the total mean score of nurses' knowledge was difference between before and after implementation of nursing guidelines sessions, its total mean score was $(17.80 \pm 2.772,26.07 \pm 2.406$ in orders). A statistically significant difference was detected between two readings $(t=-12.783, p=0.000)$. These results were supported by [21] who studied the care of children post cardiac catheterization and concluded that, the mean total score for nurses' knowledge working in $\mathrm{CC}$ between pre/post interventions had significant difference at $p<0.001$. There was significance correlation between level of nurse's knowledge and early detection and management of complications post CC. In the researcher point of view nurses play a pivotal role in recognizing and managing $\mathrm{CC}$ complications and must be knowledgeable of the potential complications and their management.

The current study illustrated that more than two fifth of the assigned nurses had unsatisfactory level of knowledge before implementation of the nursing guidelines sessions. However, all cardiac catheterization team should demonstrate adequate knowledge and deep understanding that help them to provide effective care for children after CC. Nurses ought to be able to describe potential complications of each procedure and outline methods of its management.

Regarding to the nurses ability to assess of the presence, weakness or absence of peripheral pulse for children, the results of the current study demonstrated that, a great difference was detected between pre and post nurses observational checklists after application of nursing guidelines sessions.

These results were supported by [22] who found that, specific management of a child post-CC must utilize strategies such as continuous follow-up of child peripheral pulse to reduce the risk of complications. In addition monitoring of the child after $\mathrm{CC}$ is fundamental for early identification and management of complications. All of nurses who able to promptly detect complications are in the optimal position and frequently checked for site of pulse to prompt critical action and improve child outcomes. The majority of complications including bleeding and haematoma occurred post procedure, so frequent nursing monitoring in the first hours is effective in decreasing these complications [23]

The current study showed that, a great difference was detected between pre and post nurses observational checklists about puncture site assessment after application of nursing guidelines sessions for children post CC. This result supported by another study held by [24] who retrospectively studied the complications that occurred post $\mathrm{CC}$, and confirmed that nurses must provide neurovascular limb ob- 
servations including blood pressure, heart rate, groin site assessment and subsequent loss of sensation. As well as notify the physician if an extremityis cold, discolored, and has a diminished or absent of distal pulse.

As regarding to nurses' practice, it was evident from the current study that the total means scores of nurses' practice about care for children after CC was difference between before and after implementation of nursing guidelines sessions, it was $(6.27 \pm 1.311,13.80 \pm 1.883$ in orders). Statistically significant difference was detected between two readings ( $t=-18.175, p=0.000)$. Our aim from these guidelines was to assist nursing staff to improve clinical practice and children outcomes for these children. Monitoring of the children after $\mathrm{CC}$ that is essential for early identification and management of complications and emphasizes the need for this guideline because complications associated with $\mathrm{CC}$ are a major cause of morbidity and mortality in children.

Regarding post cardiac catheterization vascular complications the current study revealed that, tachycardia or bradycardia, and hypotension represent the major vascular complication followed by weak and absent pulse in the study group compared with weak or absent pulse then hypotension followed by tachycardia and bradycardia in which the rate of incidence was higher in the control group than in study group. On the same line, our result agree with a study at Sohag university hospital held by [4] who studied the adverse events in pediatric cardiac catheterization, reported that, vascular complications represented the majority in which 12 child (38.7\%) who suffered temporary loss of femoral artery pulsation. Concerning bleeding which was present in one case of the study group that result agree with [25] who clarified that one patient who suffered significant bleeding at the puncture sites and required blood transfusion compared with 5 patient in the control group.

The results of the current study revealed that, almost of children in the study don't complain from hematoma compared to more than three quarters in the control group. These results were supported by [26] who indicated that all children post cardiac catheterization admitted to $\mathrm{CCU}$ for 6 to 8 hours to monitored physiological stability and observe signs of complication such as hypotension, arrhythmia, hematoma which occur in $20 \%$ of children post CC.

As regards post $\mathrm{CC}$ complications among children in both groups, the current study showed that
$3.3 \%$ of children in study group were exposed to bleeding compared with children in the control group $16.7 \%$ and also insertion site hematoma (3.3\% \& $23.3 \%$ in order). It supported by a recent study held by [26] about Complications of Cardiac Catheterization in Structural Heart Disease who found that vascular bleeding was $(1,01 \%)$ and vascular thrombosis was $0,72 \%$.

It was contradicted with an Egyptian study held by [4] about adverse events in pediatric cardiac catheterization: Initial experience of Sohag University hospital who found that $18.1 \%$ of patients had severe bleeding from femoral vein requiring blood transfusion due to no adequate compression after removal of sheath and no adequate observation. In our study there is low incidence of bleeding and hematoma, which may be due to early detection of them and close observation.

It was found in the current study that the vast majority of children in study group don't have weak or absent pulse, while half of children in control group have weak or absent pulse. Fortunately, it was found in the current study that no occurrence of Oliguria and aspiration in children of study group, while it occurred in control group with equal percentage of $13.3 \%$. These results were supported by [27] who concluded in their study that, $10 \%$ of children after cardiac intervention can complain from urine retention and $12 \%$ of children can occur complication from anesthesia such as aspiration or loss of conscious.

The current study proved that there was statistically significant correlation detected between the nurses' total mean score of practice after implementation of nursing guidelines sessions and selected post cardiac catheterization complications such as presence of hypothermia and presence of tachy or bradycardia among children of the study group. Majority of complications including bleeding, haematoma and hypothermia occurred within the first hours post cardiac catheterization. It may be interpretive by frequent nursing monitoring of children in the first hours is effective in early detection and decreasing complications.

On the same context a study held by [28] who retrospectively studied in different institutions have varying times for child mobilization after cardiac catheterization, $24.1 \%$ mobilize patients after 4 hours, $55.2 \%$ after 6 hours, and $20.65 \%$ after 8 hours. There was statistical significance correlation between fixation of child's leg for at least 4 hours and less occurrence of bleeding and hematoma. 


\section{Conclusion:}

The results of the current study concluded that after implementation of the nursing guidelines, there was significant improvement in the level of knowledge among nurses in the current study. Children in the study group exposed to less post cardiac catheterization complications such as (weak or absent pulse, hypotension and hypothermia) less than children in the control group. There was statistically significance difference between the total mean score of nurses' knowledge after implementation of nursing guidelines.

\section{Recommendations:}

Based on the results of the current study, it was recommended that:

- Raising the awareness of pediatric nurses through in-service training sessions about the post cardiac catheterization nursing guidelines and its benefits on occurrence of complications.

- Simple Arabic illustrated booklet about cardiac catheterization care for children undergoing $\mathrm{CC}$ should be available in every post $\mathrm{CC}$ unit.

- Increasing the mothers knowledge through instruction session about (home care, late post CC complications, child follow-up).

- Longitudinal study is necessary to monitor the late post $\mathrm{CC}$ complications.

\section{References}

1- HOCKENBERRY M.J., WILSON D. and RODGERS C.C.: Wong's essentials of pediatric nursing. Elsevier Health Sciences, 2016.

2- THRUSH P.T. and HOFFMAN T.M.: Pediatric heart transplantation-indications and outcomes in the current era. Journal of tHoracic Disease. Jun., 26, 6 (8): 108096, 2014.

3- KANTER J.P., BERGERSEN L., COOMBS S., FORBES T.J., EVERETT A.D. and MARTIN G.R.: Pediatric Cardiac Catheterization Databases. In Pediatric and Congenital Cardiac Care. (pp. 243-257). Springer London, 2015.

4- ALI S.H.: Adverse events in pediatric cardiac catheterization: Initial experience of Sohag university hospital. The Egyptian Heart Journal. Mar., 31, 68 (1): 45-51, 2016.

5- PARK T.K., YANG J.H. and CHOI S.H.: Endovascular Repair Using Suture-Mediated Closure Devices and Balloon Tamponade following Inadvertent Subclavian Artery Catheterization with Large-Caliber Hemodialysis Catheter. Korean Circulation Journal. Jul., 1, 46 (4): 584-7, 2016.

6- BRUNEAU B.G. and SRIVASTAVA D.: Congenital Heart Disease. Circulation Research, Feb. 14, 114 (4): 598-9, 2014.

7- ALLEN H.D., BEEKMAN III R.H. and GARSON Jr. A.: AHA scientific statement: Pediatric therapeutic cardiac catheterization: A statement for healthcare professionals from the council on cardiovascular disease in the young. American Heart Association. Circulation, 97: 609-25. http://besancon-cardio.org/recommandations/interven pdf, 2011

8- ARMSBY L.B., VINCENT R.N., FOERSTER S.R., HOLZER R.J., MOORE J.W., MARSHALL A.C., LATSON L. and BROOK M.: Task Force 3: Pediatric cardiology fellowship training in cardiac catheterization. Circulation. Aug., 11, 132 (6): e68-74, 2015.

9- GREGORY D., MIDODZI W. and PEARCE N.: Complications with Angio-SealTM Vascular Closure Devices Compared with Manual Compression after Diagnostic Cardiac Catheterization and Percutaneous Coronary Intervention. Journal of Interventional Cardiology. Dec., 1, 26 (6): 630-8, 2013.

10- CAVALCANTE A.M., BRUNORI E.H., LOPES C..T, SILVA A.B. and HERDMAN T.H.: Nursing diagnoses and interventions for a child after cardiac surgery in an intensive care unit. Revista Brasileira de Enfermagem. Feb., 68 (1): 155-60, http://dx.doi.org/10.1590/00347167.2015680121i, 2015.

11- KUMAR P., JOSHI V.S. and MADHU P.V.: Diagnostic pediatric cardiac catheterization: Experience of a tertiary care pediatric cardiac centre. Medical Journal Armed Forces India. Jan., 31, 70 (1): 10-6, 2014.

12- MIYATA S., CHO J., MATSUSHIMA K., FOWLER A. and BLISS D.W.: Operative outcomes of infantile hypertrophic pyloric stenosis in patients with congenital heart disease. Journal of Pediatric Surgery. Nov., 30, 51 (11): 1755-8, 2016.

13- SOBHY R., EL-SISI A., FATTOUH A.M., AGHA H.M., EL-SAIEDI S.A., ATTIA W., ABDELAZIZ D.M. and HAMZA H.: Transcatheter closure of perimembranous ventricular septal defects (VSDs) using the Amplatzer duct occluder I device. Progress in Pediatric Cardiology. Dec., 16, 2016.

14- SANAP R., PRABHU S., SHIVPUJE S. and BANSAL N.O.: Our experience of percutaneous ventricular septal device closure at our centre (tertiary care)-Retrospective study. Indian Heart Journal. (66): S51, 2014.

15- EGBE A., UPPU S., STROUSTRUP A., LEE S., HO D. and SRIVASTAVA S.: Incidences and sociodemographics of specific congenital heart diseases in the United States of America: An evaluation of hospital discharge diagnoses. Pediatric cardiology. Aug., 1, 35 (6): 975-82, 2014.

16- GHELANI S.J., GLATZ A.C., DAVID S., LEAHY R., HIRSCH R., ARMSBY L.B., TRUCCO S.M., HOLZER R.J. and BERGERSEN L.: Radiation dose benchmarks during cardiac catheterization for congenital heart disease in the United States. JACC: Cardiovascular Interventions. Sep., 30, 7 (9): 1060-9.

17-EL-ABD D.M., SAID R.N., HANNA B.M., EL-NAGGAR N.F.: Maternal and offspring methylenetetrahydrofolate reductase gene C677T polymorphism: Does it influence the prevalence of congenital heart defects in Egyptian neonates?. Comparative Clinical Pathology. Mar., 1, 23 (2): $317-22,2014$.

18- IBRAHIM M.A., AHMED E.M., EZZ M.A. and MOHAMED S.A.: Impact of nursing management protocol on selected postoperative outcomes among children with open heart surgery at Cairo University Specialized Pedi- 
atric Hospital. Journal of American Science. Jan., 1, 8 (12), 2012.

19- TERRI KYLE and SUSAN CARMAN: nursing care of child cardiovascular Disorders Page 645, 2013.

20- ABD-ELSHAFY S.K., KHALAF G.S., ABO-KERISHA M.Z., AHMED N.T., EL-AZIZ M.A., MOHAMED M.A.: Not all sounds have negative effects on children undergoing cardiac surgery. Journal of cardiothoracic and vascular anesthesia. Oct., 31, 29 (5): 1277-84, 2015.

21- YU M., CHOI K.C., WONG E.M., SIT J.W. and IP W.Y.: Effect of early ambulation after transfemoral cardiac catheterization in Hong Kong: A single-blinded randomized controlled trial/Hong Kong'ta transfemoral kardiyak kateterizasyon sonrasi erken ambülasyonun etkisi: Tek-kör randomize kontrollü bir çalisma. Anadulu Kardiyoloji Dergisi: AKD. 2012 May, 1, 12 (3): 222.

22- ASANI M., ALIYU I. and KABIR H.: Profile of congenital heart defects among children at Aminu Kano Teaching Hospital, Kano, Nigeria. Journal of Medicine in the Tropics, 15 (2): 13 1, 2013.

23- HOCKENBERRY M.J., and WILSON D.: Wong's nursing care of infants and children. Mosby/Elsevier. Peds Chapter 29 Retrieved from. http://online.vitalsource.com/books/ 9780323069120/id/B9780323069120000341_p0925, 2011.
24- HARPER J.P.: Post-diagnostic cardiac catheterization: development and evaluation of an evidence-based standard of care. Journal for Nurses in Professional Development. Nov., 1, 23 (6): 271-6, 2007.

25- LAGE K., GREENWAY S.C., ROSENFELD J. A., WAKIMOTO H., GORHAM J. M., SEGRE A. V. and MESQUITA S. M.: Genetic and environmental risk factors in congenital heart disease functionally converge in protein networks driving heart development. Proceedings of the National Academy of Sciences, 109 (3 5): 14035-14040, 2012.

26- LEE K.E., SEO Y.J., KIM G.B., AN H.S., SONG Y.H., KWON B.S., BAE E.J. and NOH C.I.: Complications of Cardiac Catheterization in Structural Heart Disease. Korean Circulation Journal, Mar., 1, 46 (2): 246-55, 2016.

27- MORRISON L.J., NEUMAR R.W., ZIMMERMAN J.L., LINK M.S., NEWBY L.K., MCMULLAN P.W., HOEK T.V., HALVERSON C.C., DOERING L., PEBERDY M.A. and EDELSON D.P.: Strategies for improving survival after in-hospital cardiac arrest in the United States: 2013 consensus recommendations. Circulation, Apr., 9, 127 (14): 1538-63, 2013.

28- BRUNEAU B.G. and SRIVASTAVA D.: Congenital Heart Disease. Circulation Research. Feb., 14, 114 (4): 598-9. ch, 114 (4): 598-599, 2014.

\title{
تأثير إرشادات تمريضية للممرضات على حلدوث مضاعفات مختارة ما بعد القسطرة القلبية العلاجية فيلى الأطفال
}

\author{
لقد أحدثت قسطرة القلب للأطفال. وهى عبارة عن إجراء يستخدم للتدخل فى علاج بعض التشوهات والأعتلالات فى قلب الأطفال،

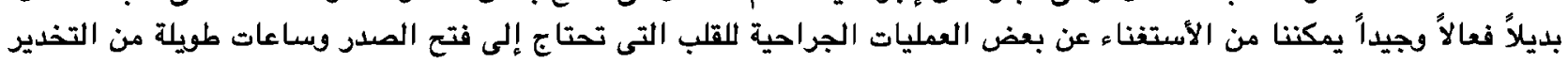

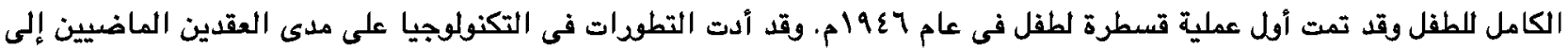

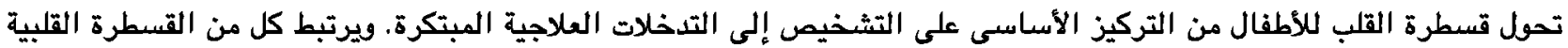 \\ التشخيصية والعلاجية مع مضاعفات مختلفة. \\ كان هدف الدراسة الحالية تقييم تأثير إرشادات تمريضية للممرضات على حدوث مضاعفات مختارة ما بعد القسطرة القلبية العلاجية \\ فى الأطفال.

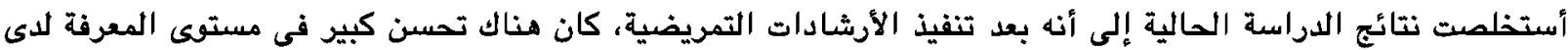

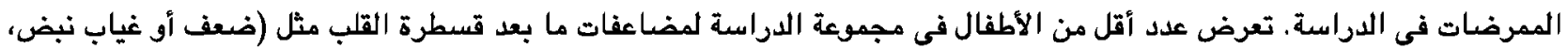

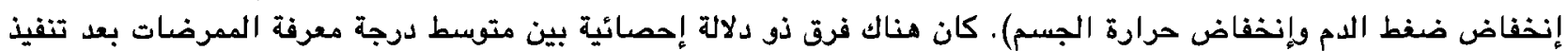 \\ الآرشادات التمريضية.
}

